\title{
Parameters influencing the transport rate of marker compounds across Caco-2 monolayers
}

\author{
M. Wirth", E. Bogner, F. Gabor \\ Institute of Pharmaceutical Technology and Biopharmaceutics, University of Vienna \\ Althanstr. 14, A-1090 Vienna, Austria
}

\begin{abstract}
Performing transport experiments with Caco-2 monolayers some important parameters have to be considered. Cell layers are appropriate for transport studies after complete polarisation and differentiation. Consequently they should be used $20-25 \mathrm{~d}$ after seeding. Monolayers grown for shorter time than $20 \mathrm{~d}$ yield to high transport rates, a cultivation period longer than $25 \mathrm{~d}$ results in layers susceptible to detachment. Additionally the material of the filter support exerts an influence on the transport data because of varying barrier functions of cell layers grown on polyester- versus polycarbonate filter inserts. By comparison of transport rates obtained with different model systems such as Transwells and Ussing chambers the influence of the unstirred water layer on permeation of markers was investigated. The results indicate that there is a noticeable difference with hydrophobic compounds only. To check the dependence of transport phenomena on energy the difference in transport rates between $4^{\circ} \mathrm{C}$ and $37^{\circ} \mathrm{C}$ as well as the cumulative transport subject to the transport direction was determined. Moreover the influence of the stirring rate on the cumulative transport in the Ussing chamber system was elucidated. For assessment of the cell associated amount of the transported substance the cell layer was dissolved in $\mathrm{NaOH}$ / SDS to get further valuable informations.
\end{abstract}

\section{INTRODUCTION}

During the last decade there was an increasing progress in the discovery and development of new drug candidates using rational drug design and recombinant DNA technology. In future the major challenge confronting pharmaceutical scientists will be the efficient delivery of these drugs to the 
site of action by appropriate drug delivery strategies (1). In an effort to optimize existing strategies and develop new ones, cell culture models gained increasing attention to study drug transport across biological barriers. In vitro cultures of cells exhibit a lot of advantages over conventional techniques such as (i) the rapid assessment of the potential permeability and metabolism of drugs, (ii) the suitability for high through-put screening and (iii) the opportunity to elucidate the pathways of drug transport as well as to evaluate formulation strategies for enhanced drug delivery. Moreover artificial tissues of human origin rather than animal tissues can be used in screening assays. Thus animal studies can be reduced to a minimum, which are time consuming, expensive and some times controversial in results (2).

In the field of investigation and characterization of intestinal absorption the Caco-2 cell culture became more and more important during the last years (3). The Caco-2 cell line was established by J. Fogh in 1974 and derived from a human colon adenocarcinoma of a 72 year-old male caucasian patient (4). Despite of their colonic origin Caco-2 cells form monolayers that undergo complete and terminal differentiation forming columnar absorptive cells with tight junctions similar to human small intestinal epithelium (5). Out of these reasons Caco-2 cells are widely used in pharmaceutical research and development for several applications $(6,7,8)$. To date Caco-2 monolayers represent a well known model for the human intestinal epithelial lining. Recently the importance of the Caco-2 cell culture was underlined in context with the Biopharmaceutics Classification System (BCS) comprising studies simulating absorption of drugs $(9,10)$.

Due to the increasing interest and importance of transport studies using cell culture models to predict absorption of potential new drugs, the aim of this work was to find out and characterize parameters influencing transport experiments with Caco-2 monolayers.

\section{MATERIALS AND METHODS}

\section{Materials}

Fluorescein-sodium, sulforhodamine 101 , fluorescein-dextran ( $M W \approx 20 \mathrm{kD})$, 4-methylumbelliferylphosphate and alkaline phosphatase (type I) were purchased from Sigma (St. Louis, MO, U.S.A.); cell culture chamber inserts (Transwell ${ }^{\circledR}$, Snapwell ${ }^{\top M}$ ) were obtained from Corning Costar Corporation (Cambridge, U.K.). 
The Caco-2 cell line was obtained from the American Type Culture Collection (Rockville, MD, U.S.A.) and used between passage 50 and 60; tissue culture reagents were from Sigma and Gibco Life Technologies Ltd. (U.K.).

All other chemicals were of analytical grade and purchased from Merck (Darmstadt, D).

\section{Cell Culture}

Caco-2 cells were cultured in Dulbecco's modified Eagle's medium (DMEM) containing 10\% fetal calf serum, $4 \mathrm{mM} \mathrm{L}$-glutamine and $150 \mu \mathrm{g} / \mathrm{ml}$ gentamycine in a humidified $5 \% \mathrm{CO}_{2} / 95 \%$ air atmosphere at $37^{\circ} \mathrm{C}$ and subcultivated by trypsination.

For drug transport studies, cells were seeded on $12 \mathrm{~mm}$ polycarbonate or polyester filter (pore width $0.4 \mu \mathrm{m}$ ) culture inserts (Transwell ${ }^{\circledast}$, Snapwell ${ }^{\mathrm{TM}}$, Costar) at a density of $6 \times 10^{4} / \mathrm{cm}^{2}$. The cells were fed every other day with culture medium and used for permeability studies between $8-24 \mathrm{~d}$ after seeding.

For estimation of cell-associated alkaline phosphatase activity, Caco-2 cells were grown on TCtreated 96-well microplates (Greiner, A) for 2-30d at a seeding density of $1,7 \times 10^{4}$ cells / well.

The run of the TEER was monitored with an Evommeter (Millicell ${ }^{\oplus}$-ERS, Millipore, U.S.A.) fitted with 'chopstick' electrodes. The resistance of the filter support and the buffer has been substracted from all TEER values quoted.

\section{Alkaline phosphatase activity}

The activity of the brush border enzyme alkaline phosphatase was measured according to a modified method of Watanabe et al. (11). In short, the Caco-2 monolayer was incubated at $37^{\circ} \mathrm{C}$ with $50 \mu \mathrm{l}$ $3 \mathrm{mM}$ 4-methylumbelliferylphosphate in isotone HEPES/ $\mathrm{NaOH}$-buffer $\mathrm{pH} 9.0$. After $60 \mathrm{~min}$ the emitted fluorescence intensity was determined at $535 \mathrm{~nm}$ and calculated from a calibration curve using alkaline phosphatase.

\section{Transport Studies}

Caco-2 monolayers grown on Transwell-supports were washed twice with Hank's balanced salt solution (HBSS) and placed in 12-well microplates. Aliquots of HBSS were added to the apical $(0,5$ $\mathrm{ml}$ ) and basolateral $(1,5 \mathrm{ml})$ chamber followed by equilibration for $30 \mathrm{~min}$ at $37^{\circ} \mathrm{C}$. After measuring the TEER, the buffer in the apical compartment was replaced by $500 \mu \mathrm{l}$ of a $0.1 \mathrm{mM}$ solution of the 
compound under investigation in HBSS. The transport rate from the apical to the basolateral compartment was determined at certain intervals over a period of $4 \mathrm{~h}$ at $37^{\circ} \mathrm{C}$. Every $30 \mathrm{~min}$ an aliquot of $50 \mu \mathrm{l}$ was withdrawn from the receptor chamber and replaced by HBSS. The relative fluorescence intensity of the compound of interest was measured using a Spectrafluor fluorometer (TECAN, A). The transport rates of the compounds through the filter support without cell layer served as a control.

For the Ussing chamber experiments Caco-2 cells were cultivated on Snapwell supports. After washing twice with HBSS, the inserts were fitted into the Ussing chamber. Each compartment was filled with $4.0 \mathrm{ml} \mathrm{HBSS}$ and the monolayers were equilibrated for $30 \mathrm{~min}$ at $37^{\circ} \mathrm{C}$ and $4^{\circ} \mathrm{C}$, respectively. After removing $1.0 \mathrm{ml}$ HBSS from the donor chamber, $1.0 \mathrm{ml}$ solution containing the test compound was added to yield a final concentration of $0.1 \mathrm{mM}$ in the apical chamber. Transport rates were determined over a period of $4 \mathrm{~h}$ at either $37^{\circ} \mathrm{C}$ or $4^{\circ} \mathrm{C}$. Samples were collected and analyzed as described above.

\section{Determination of the cell associated amount of test compound}

At the end of the transport experiments, the monolayers were washed twice with HBSS to remove supernatant compounds and inserted in 24-well microplates containing $400 \mu \mathrm{l}$ of $0.1 \mathrm{~N} \mathrm{NaOH} / 5 \%$ SDS per well. After addition of $200 \mu \mathrm{l}$ of $0.1 \mathrm{~N} \mathrm{NaOH} / 5 \%$ SDS to the apical surface the cell layer was incubated for $15 \mathrm{~h}$ at room temperature to dissolve the cell layer. The filter support was removed and the solution was gently mixed pior to fluorimetric analysis.

\section{Data handling}

Transport data were quoted as cumulative amount of solute in the receiver chamber and calculated as percentage of compound added. Considering both, the different ratio of chamber volumes in Transwell-systems and Ussing chambers and the transport across cell-free membranes, the quotient of the cumulative transport rate across the cell barrier and the filter support without monolayer was calculated. This so-called 'fraction absorbed' was used for comparison of the transport data concerning the different model systems and membrane materials. 


\section{RESULTS AND DISCUSSION}

The objective of this work was to evaluate the critical parameters in the use of Caco- 2 cells for transport studies. One of the crucial parameters for proper barrier function of Caco-2 monolayers is the cultivation period of cells on permeable filter supports (12). The transepithelial electrical resistance (TEER) was monitored to assess the integrity of the monolayers and the development of tight junctions. Not only the tightness of the monolayer, but also the functional differentiation is important for appropriate transport characteristics. Consequently the activity of the brush border enzyme alkaline phosphatase was determined and used as a marker for functional differentiation. To find out the cultivation period necessary for the development of monolayers with suitable transport characteristics, the TEER and alkaline phosphatase activity was tested over a period of 30d. As indicated by figure 1 the TEER rises at day 3 and increases continously until day 20 yielding $450 \pm$ $40 \Omega . \mathrm{cm}^{2}$. The activity of the alkaline phosphatase located at the apical side of the cell layer reached the maximum $22 \mathrm{~d}$ after seeding. Corresponding to data from the literature, these values indicate for integrity and formation of monolayers within three weeks of cultivation $(12,5)$.

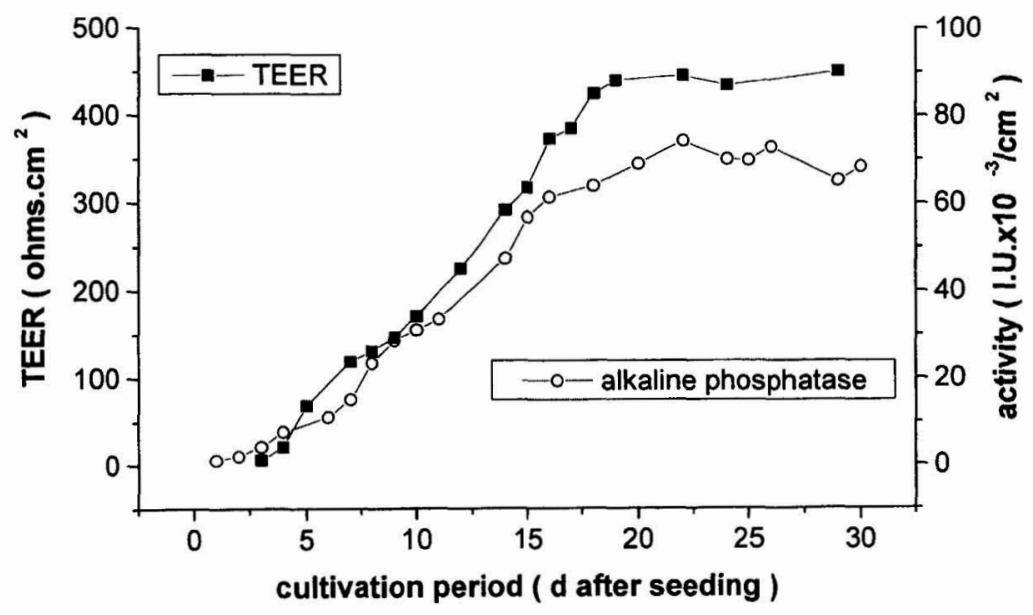

Figure 1: TEER and alkaline phosphatase activity of Caco-2 monolayers versus cultivation period 
To get an idea of the relationship between TEER and functional differentiation on the one hand and transport characteristics of Caco-2 layers on the other hand transport studies were performed using three marker substances of different hydrophilicity and size. To include the impact of the cultivation period, these experiments were carried out with Caco-2 monolayers grown on polyester-Transwellinserts for $8,12,15,19$ and $21 \mathrm{~d}$, respectively. According to figure 2 the transport rates of all compounds decreased markedly concurrent with prolonged cultivation, whereas the TEER values increased: the cumulative transport through monolayers grown for $21 \mathrm{~d}$ was only about $22 \%$ in case of fluorescein- $\mathrm{Na}$ or $16 \%$ in case of sulforhodamine compared to the transport rates of cell layers cultivated for $8 \mathrm{~d}$. This decrease in transport rates is consistent with an increase in TEER values from $160 \pm 30 \Omega \cdot \mathrm{cm}^{2}$ (cultivation period $8 \mathrm{~d}$ ) to $518 \pm 50 \Omega \cdot \mathrm{cm}^{2}$ (cultivation period 21d). Accordingly the transport rate of F-dextran decreased with increasing cultivation period resulting in complete inability of permeation across the monolayers cultured for 19 or $21 \mathrm{~d}$. Due to its high molecular weight, F-dextran can permeate through the leaky monolayer, but upon full differentiation and tightness the marker is inhibited from overcoming the barrier.

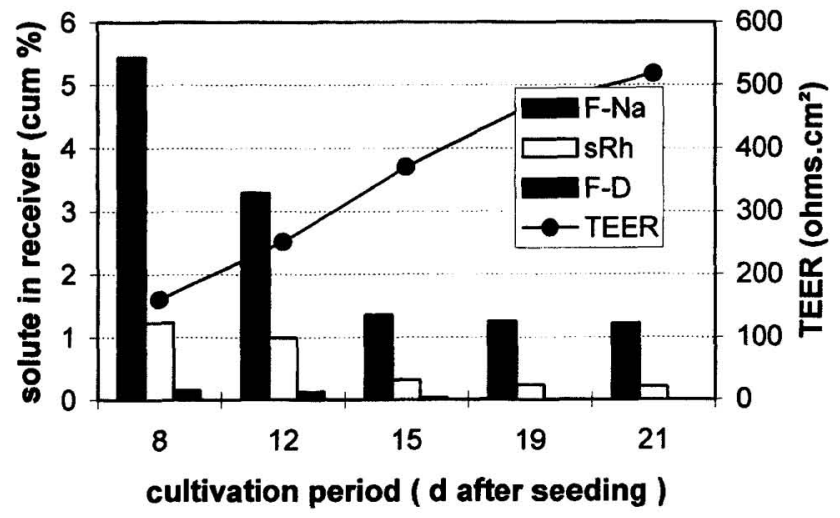

Figure 2: Dependence of cumulative transport of marker compounds from cultivation of Caco-2 monolayers

F-Na: fluorescein-Na; sRh: sulforhodamine; F-D: fluorescein-dextran 
Since the transport rates of marker compounds decreased so far and not further (data not shown) and an increase in TEER as well as alkaline phosphatase activity was not observed after cultivation of the Caco-2 monolayers for $21 \mathrm{~d}$, it is likely that the barrier function of the artificial tissue is fully developed at that time. Following on from these results, it is recommended to use the monolayers exclusively $20-24 \mathrm{~d}$ after seeding. Prolonging the cultivation period results in monolayers with high susceptibility to detachment of the cells from the supporting matrix. Accordingly the following experiments were carried out with Caco-2 monolayers grown for $22 \mathrm{~d}$.

To identify further parameters influencing transport data the impact of the supporting matrix and the transport device was investigated. Transport studies were performed for $4 \mathrm{~h}$ at $37^{\circ} \mathrm{C}$ using polyesteras well as polycarbonate-inserts in Transwell-systems and an Ussing chambers, respectively. The concentration of marker added to the apical chamber was $0.1 \mathrm{mM}$. Since the ratio between the donor and the acceptor volumes are different in both transport models, neither cumulative transport rates nor apparent permeabilities represent parameters suitable for comparison. Additionally the transport rate across the filter support without monolayer should be included in the calculations as far as possible. Therefore the 'absorbed fraction' was calculated considering the amount of marker transported through the sole supporting matrix ( see fig. 3).

Any transport of F-dextran was not measured at all. The transport rate of fluorescein-Na through Caco-2 monolayers grown on polycarbonate inserts was about 1,6fold higher compared to polyester inserts. Using sulforhodamine as a marker noticeable differences between monolayers grown on polycarbonate- and polyester-membranes could not be detected. With regard to the transport models only slight differences in the transport rates of fluorescein-Na between the Transwell- and the Ussing chamber system were observed. On the other hand the transport of sulforhodamine was more different in stationary and stirred model systems. The transported fraction of sulforhodamine in the Ussing chamber exceeded that of the Transwell-system about 5,4fold. In Ussing chambers the transport rates of fluorescein- $\mathrm{Na}$ and sulforhodamine through cell layers grown on polyester membranes were comparable. Using cells grown on polycarbonate inserts the absorbed fraction slightly increased in case of fluorescein-Na. 


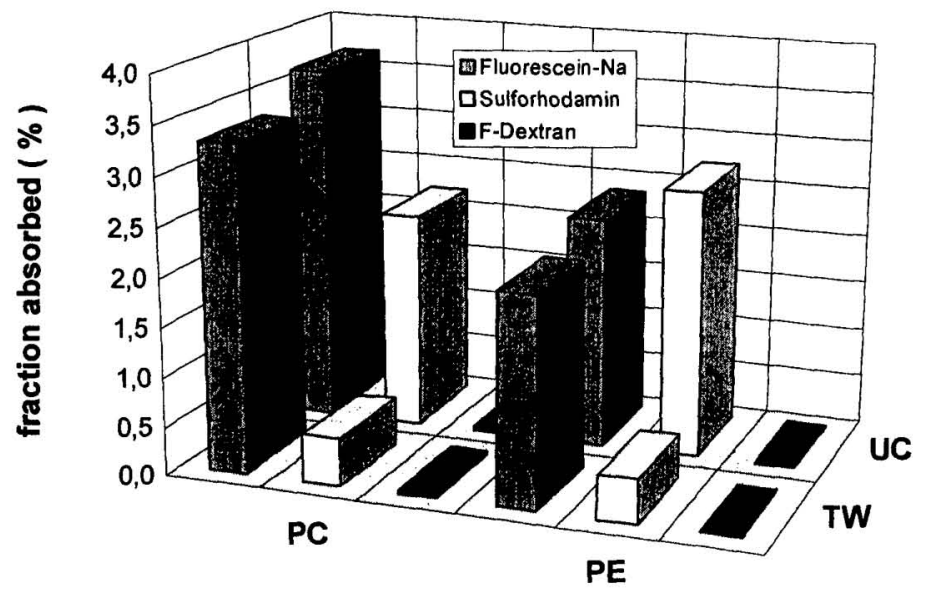

Figure 3: Comparison of transport rates through polyester- and polycarbonate-membranes in the Transwell-system and the Ussing chamber-model

PC: polycarbonate; PE: polyester; TW: Transwell-system; UC: Ussing chamber-model

The rather huge difference in sulforhodamine transport between the stationary and the stirred model system was probably due to the influence of the unstirred water layer (UWL): in the Transwellsystem the presence of a rather thick UWL decreased the transport rate across the cell barrier. But in the Ussing chamber system the UWL-thickness was reduced markedly by stirring and resulted in higher transport rates $(13,14)$. Contrarily the transport rates of fluorescein-Na were not increased in Ussing chambers. This might be due to the more hydrophilic nature of the molecule, which influences the permeation through the UWL to a quite lower extent. The slight increasing transport of fluorescein-Na across monolayers grown on polycarbonate filters might result from lower barrier function of these monolayers since fluorescein- $\mathrm{Na}$ is transported predominantly via the paracellular route. Nevertheless F-dextran exhibiting a molecular weight of about $20 \mathrm{kDa}$ is excluded from transport.

To get evidence for the transport processes involved transport studies were conducted at different temperatures. To avoid influences of the UWL these experiments were carried out using the Ussing 
Chamber system. Transport rates of all three markers were determined using Caco-2 monolayers grown for $22 \mathrm{~d}$ setting the temperature to $4^{\circ} \mathrm{C}$ and $37^{\circ} \mathrm{C}$ throughout the experiments, respectively.

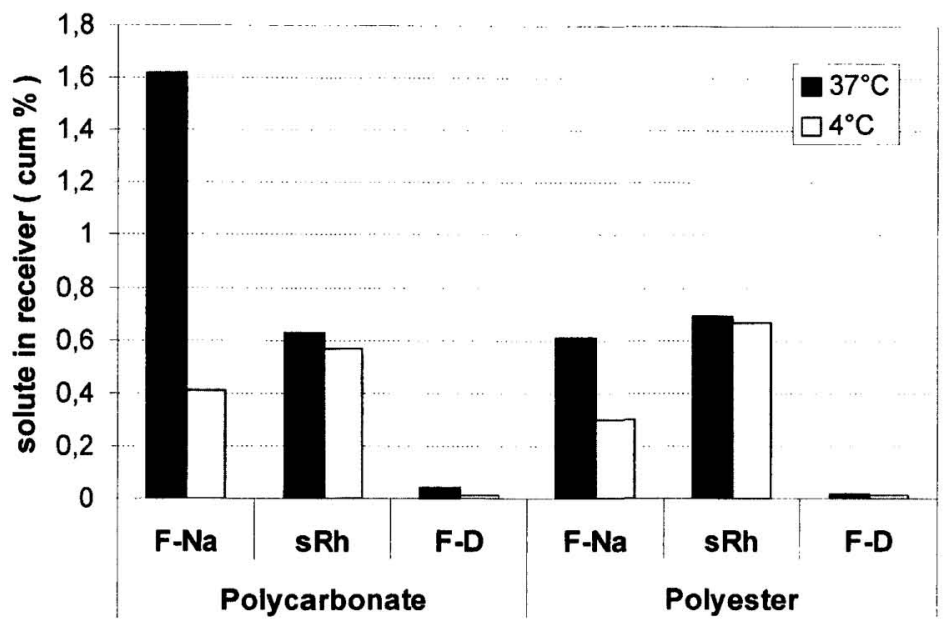

Figure 4: Transport rates of markers at different temperature levels

F-Na: fluorescein-Na; sRh: sulforhodamine; F-D: fluorescein-dextran

As indicated by figure 4 the transport rates of sulforhodamine and F-dextran at $37^{\circ} \mathrm{C}$ only slightly exceeded that at $4^{\circ} \mathrm{C}$, but the $\mathrm{F}$-dextran transport was rather negligible at both temperature levels. This indicates for prevailing passive transport processes. The vast increase in fluorescein- $\mathrm{Na}$ transport at $37^{\circ} \mathrm{C}$ compared to $4^{\circ} \mathrm{C}$ might be due to involvement of active transport processes of the hydrophilic marker across Caco-2 monolayers. Interestingly the difference between $4^{\circ} \mathrm{C}$ and $37^{\circ} \mathrm{C}$ was much more distinct with monolayers grown on polycarbonate filters than on polyester inserts. Since the difference between polyester- and polycarbonate inserts was only $1: 1.4$ at $4^{\circ} \mathrm{C}$ as opposed to $1: 2.7$ at $37^{\circ} \mathrm{C}$, this effect could not be explained solely by poor barrier function of the cell layer as mentioned above. Obviously an additional effect contributed to the transport rates of the marker compounds at $37^{\circ} \mathrm{C}$. The higher transport rates of sulforhodamine at $4^{\circ} \mathrm{C}$ (calculated $\log \mathrm{P} 1.58$ ) might be due to its higher lipophilicity as compared to fluorescein-Na exhibiting a calculated $\log \mathrm{P}$ of 0.49 . 
Additional transport studies were carried out to check whether the transport rate of the marker compounds depends on the direction of transport. Since there was no considerable transport of Fdextran these experiments were performed with fluorescein- $\mathrm{Na}$ and sulforhodamine using Caco-2 monolayers grown on polyester inserts for $22 \mathrm{~d}$ in Ussing chambers at $4^{\circ} \mathrm{C}$ and $37^{\circ} \mathrm{C}$, respectively.

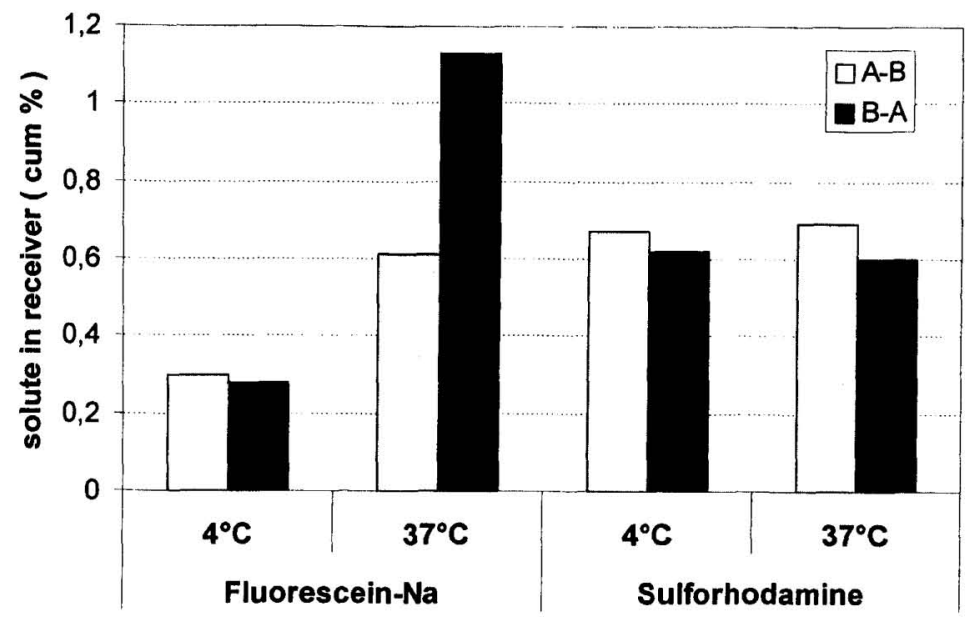

Figure 5: Influence of the direction of transport on cumulative transport of marker compounds A-B: apical to basolateral; B-A: basolateral to apical

As indicated by figure 5 there was no relevant alteration of the transport rates of sulforhodamine upon apical to basolateral - or basolateral to apical transport at $4^{\circ} \mathrm{C}$ as well as $37^{\circ} \mathrm{C}$ pointing to passive diffusion processes exclusively. Similarily there was no difference in case of fluorescein-Na at $4^{\circ} \mathrm{C}$, but at $37^{\circ} \mathrm{C}$ the basolateral to apical transport was two times higher than apical to basolateral transport. This indicated for involvement of active transport processes. As the fluorescein- $\mathrm{Na}$ transport was reported to be subject to p-glycoproteid activity (15), it is likely that the lower apical to basolateral transport is mediated by p-glycoproteid. 
To determine the cell associated amount of the markers transported, the monolayers were washed twice with $\mathrm{HBSS}$ and dissolved in $0,1 \mathrm{mM} \mathrm{NaOH} / 5 \% \mathrm{SDS}$ at the end of the transport experiments (16). As the cell layers used in Ussing chamber experiments were partly detached from the supporting matrix by the washing procedure, the amount of cell bound marker was determined only in the Transwell-system.

\begin{tabular}{|c|c|c|c|c|}
\hline & \multicolumn{2}{|c|}{$\begin{array}{l}\text { polycarbonate inserts } \\
\text { amount (nmol) }\end{array}$} & \multicolumn{2}{|c|}{$\begin{array}{l}\text { polyester inserts } \\
\text { amount ( } \mathrm{nmol} \text { ) }\end{array}$} \\
\hline & transported & cell associated & transported & cell associated \\
\hline Fluorescein- $\mathrm{Na}$ & 1,13 & 0,11 & 0,61 & 0,09 \\
\hline Sulforhodamine & 0,13 & 0,14 & 0,10 & 0,13 \\
\hline F-Dextran & 0,01 & $<0,01$ & $<0,01$ & $<0,01$ \\
\hline
\end{tabular}

Table 1: Transport versus cell association of markers in the Transwell-system

The results indicated that the cell association of fluorescein-Na was rather low yielding only 10 $15 \%$ of the amount transported. Bearing the detection limit in mind, the adhesion of F-dextran to the cells was as low as the transport. In case of sulforhodamine the amount of cell bound marker was noticeable higher compared to fluorescein- $\mathrm{Na}$ as cell association exceeded the cumulative transport through the cell layer.

The relative binding of fluorescein-Na and sulforhodamine was slightly higher to cells grown on polyester membranes than polycarbonate membranes. This effect might be caused by additional adhesion phenomena to the sole supporting matrix, whereby the adsorption of the marker substances is more effective in case of polyester- than polycarbonate membranes.

Finally the influence of the stirring rate on the cumulative transport in the Ussing chamber sytem was elucidated screening the transport of fluorescein-Na through Caco-2 monolayers grown on polyester inserts. Thus the gas lift of the system was set to 5,15 and $40 \mathrm{ml} / \mathrm{min}$, respectively. The transport rate was highest at $15 \mathrm{ml} / \mathrm{min}$ as indicated by an absorbed fraction of $2.33 \%$. Setting the gas lift to $40 \mathrm{ml} / \mathrm{min}$ reduced the transport rate to about $40 \%$ of the data obtained at $15 \mathrm{ml} / \mathrm{min}$. At the gas flow of $5 \mathrm{ml} / \mathrm{min}$ the transport rate of fluorescein-Na decreased to about $25 \%$ compared to 
$15 \mathrm{ml} / \mathrm{min}$. This indicates that the setting of the gas lift greatly influenced the transport data obtained. Consequently the stirring rate has to be optimized to obtain valuable data, as both to low as well as to high settings notably diminish the transport rates.

\section{CONCLUSIONS}

To date transport studies using Caco-2 monolayers are widely used in pharmacy for instance to evaluate new strategies in drug delivery $(10,17,18)$. The objective of this study was to summarize parameters being most important for proper assessment of transport data. Out of this reason the transport characteristics of three commonly used marker compounds - fluorescein-Na, sulforhodamine and F-dextran (MW 20kD) - were determined using different cultivation periods of the cell layer, filter support materials, model systems, temperature levels and transport directions $(17,19,20,21)$.

As indicated by the transport rates obtained from experiments using monolayers of varying cultivation periods, cell layers should be used for transport experiments $20 \mathrm{~d}$ after seeding at the earliest. At that time the TEER values and the alkaline phosphatase activity came up to a constant maximum and the transport data of all marker compounds under investigation were not altered, when monolayers of $19-21 \mathrm{~d}$ in culture were used. Additionally cell layers cultivated for $25 \mathrm{~d}$ or longer sometimes are susceptible to detachment from the supporting matrix during the transport experiments.

Concerning the material of the filter inserts no differences between polycarbonate and polyester were observed during transport of sulforhodamine and F-dextran. Upon use of fluorescein-Na as a marker the transport rates across the cell layer grown on polycarbonate membranes were slightly higher than that with polyester inserts indicating that the paracellular barrier is more distinct in monolayers grown on polyester supports.

The influence of the unstirred water layer was investigated by comparison of transport data obtained with stirred and unstirred model systems, respectively. In case of more hydrophilic marker compounds such as fluorescein-Na and F-dextran the cumulative transport was comparable upon use of the Transwell-system and Ussing chambers. In contrast, the sulforhodamine transport was very low in the Transwell-system, but increased markedly in the stirred Ussing chamber model, which was probably due to the lipophilicity of this marker. 
To confine the transport phenomena to the processes at the cellular level, transport experiments at different temperatures and in different transport directions were carried out using the Ussing chamber model. The aim of this investigations was to check the extent to which differences in the transport route can be confirmed by these parameters. Similar transport rates of sulforhodamine and F-dextran at $4^{\circ} \mathrm{C}$ and $37^{\circ} \mathrm{C}$ exhibiting only a slight increase at $37^{\circ} \mathrm{C}$ indicated for predominance of passive transport processes. In contrast, fluorescein-Na permeated Caco-2 monolayers at $37^{\circ} \mathrm{C}$ notedly better than at $4^{\circ} \mathrm{C}$, probably due to involvement of active transport processes. The increased transport rate of sulforhodamine at $4^{\circ} \mathrm{C}$ compared to fluorescein-Na might be due to its higher lipophilicity. Sulforhodamine was predominantly transported passively across Caco-2 monolayers as there was no difference in the cumulative transport subject to the direction of transport. Additionally no change in the transport rate of fluorescein-Na from apical-basolateral or vice versa was observed at $4^{\circ} \mathrm{C}$ indicating passive transport exclusively. But at $37^{\circ} \mathrm{C}$ its transport in the basolateral-apical direction was almost two-fold higher than the apical-basolateral transport. This phenomenon might be due to the p-glycoproteid activity in Caco-2 cells. Along with the difference in cumulative transport between $4^{\circ} \mathrm{C}$ and $37^{\circ} \mathrm{C}$ these results confirm the presence of active transport processes involved in permeation of fluorescein-Na.

Concerning the stirring rate in the Ussing chamber system, the influence of the gas flux on the transport rate was elucidated. The results pointed out that the stirring rate has to be optimized to obtain valuable data.

Finally the amount of cell associated marker compound was determined after dissolution of the cells in $0,1 \mathrm{M} \mathrm{NaOH} / 5 \%$ SDS. Cell binding to polyester membranes was marginally higher than to polycarbonate inserts for both, fluorescein-Na and sulforhodamine. But relevant differences could not be detected between the two different filter support materials. Cell association with fluorescein$\mathrm{Na}$ was considerably lower than with sulforhodamine. Probably this effect resulted from active transport processes involved in the transport of fluorescein-Na.

All in all Caco-2 monolayers are appropriate for use in transport studies 20-25d after seeding. Careful selection of the filter support matrix is recommended due to its potential influence on the transport rates obtained. Regarding the cumulative transport there is no remarkable difference between the Transwell-system and the Ussing chamber with hydrophilic compounds; but the 
transport rates of hydrophobic substances increase noticeably upon use of the Ussing chamber model. Transport studies performed at different temperatures and in different transport directions are useful to elucidate the transport processes involved. The optimization of the stirring rate in the Ussing chamber system is a further important parameter to get proper results from transport experiments using cell culture systems.

\section{REFERENCES}

1 Borchardt R.T. (1995), J. Drug Targeting 3: 179

2 Audus K.L., Bartel R.L., Hidalgo I.J., Borchardt R.T. (1990), Pharm. Res. 7: 435

3 Delie F., Rubas W. (1997), Crit. Rev. Therapeutic Drug Carrier Systems 14: 221

4 Fogh J. (1977), J. Natl. Cancer Inst. 59: 221

5 Hidalgo I.J., Raub T.J., Borchardt R.T. (1989), Gastroenterology 96: 736

6 Hilgers A.R., Conradi R.A., Burton P.S. (1990), Pharm. Res. 7: 902

7 Walgren R.A., Walle T. (1999), J. Pharm. Pharmacol. 51: 1037

8 Borchardt R.T. (1999), J. Contr. Rel. 62: 231

9 Lennernas H. (1997), J. Pharm. Pharmacol. 49: 627

10 Saha P., Kou J.H. (2000), Eur. J. Pharm. Biopharm. 50: 403

11 Watanabe F., Takano M., Tanaka F., Amino N., Hayashi C., Miyai K. (1979), Clin. Chim. Acta 91: 273

12 Wilson G., Hassan I.F., Dix C.J., Williamson I., Shah R., Mackay M., Artursson P. (1990), J. Contr. Rel. 11: 25

13 Hidalgo I.J., Hillgren K.M., Grass G.M., Borchardt R.T. (1991), Pharm. Res. 8: 222

14 Karlsson J., Artursson P (1992), Biochim. Biophys. Acta 1111: 204

15 Sakai M., Noach A.B., Blom-Roosemalen M.C.M., de Boer A.G., Breimer D.D. (1994), Biochem. Pharmacol. 48: 1199

16 Ertl B., Heigl F., Wirth M., Gabor F. (2000), J. Drug Targeting 8: 173

17 Batrakova E.V., Li S., Miller D.W., Kabanov A.V. (1999), Pharm. Res. 16: 1366

18 Thanou M.M., Kotze A.F., Scharringhausen T., Luessen H.L., de Boer A.G., Verhoef J.C., Junginger H.E. (2000), J. Contr. Rel. 64: 15

19 Biganzoli E., Cavenaghi L.A., Rossi R., Brunati M.C., Nolli M.L. (1999), Il Farmaco 54: 594

20 Sakai M., Imai T., Ohtake H., Azuma H., Otagiri M. (1999), J. Pharm. Pharmacol. 51: 27

21 Bock U., Kolac C., Borchard G., Koch K., Fuchs R., Streichhan P., Lehr C.-M. (1998), Pharm. Res. 15: 1393 